\title{
Uma perspectiva das ações sustentáveis realizadas por uma empresa do ramo de agronegócio
}

O objetivo deste artigo é apresentar as ações e estratégias que uma empresa do ramo de agronegócio têm empreendido em direção à redução de seus impacto ambientais. A análise empírica foi realizada em uma organização de porte médio localizada na região Noroeste do Estado do RS. Os dados foram coletados por meio de entrevista semiestruturada e a pesquisa é de caráter qualitativa. Os resultados demonstram que as empresas, de modo geral, têm buscado cumprir as exigências legais, correspondendo ao conceito de ação reativa, no entanto, percebe-se que há iniciativas, mesmo que em estágio inicial, de ações voltadas à preservação ambiental que correspondem ao segundo grupo: ações proativas. A pesquisa confirma que a identificação e avaliação dos impactos ambientais nas organizações, independente do setor e tamanho do empreendimento, constitui uma ferramenta importante na criação de diretrizes que codificam a gestão ambiental fundamentada na preservação do meio ambiente, contribuindo assim, para o desenvolvimento sustentável local e regional.

Palavras-chave: Impactos Ambientais; Gestão Ambiental; Práticas Empresariais; Desenvolvimento Econômico.

\section{A perspective of sustainable shares by a company of the agribusiness industry}

\begin{abstract}
The objective of this article is to present the actions and strategies that a company of the agribusiness sector has undertaken towards the reduction of its environmental impacts. The empirical analysis was performed in a medium sized organization located in the Northwest region of the State of RS. The data were collected through a semi-structured interview and the research is qualitative. The results demonstrate that the company, in general, has sought to comply with the legal requirements, corresponding to the concept of reactive action, however, it is noticed that there are initiatives, even at an early stage, of actions aimed at environmental preservation that correspond to the second group: proactive actions. The research confirms that the identification and evaluation of environmental impacts in organizations, regardless of sector and size of the enterprise, is an important tool in the creation of guidelines that codify environmental management based on the preservation of the environment, thus contributing to local sustainable development and regional levels.
\end{abstract}

Keywords: Environmental Impacts; Environmental Management; Business Practices; Economic Development.

Topic: Desenvolvimento, Sustentabilidade e Meio Ambiente

Reviewed anonymously in the process of blind peer
Received: 10/02/2019

Approved: 25/03/2019
Sandra Beatriz Vicenci Fernandes (i)

Universidade Regional do Estado do Rio Grande do Sul, Brasil http://lattes.cnpq.br/2522461975489213

http://orcid.org/0000-0001-5001-0774

sandravf@unijui.edu.br

Patricia Kischner (DD)

Universidade Regional do Estado do Rio Grande do Sul, Brasil http://lattes.cnpq.br/2522461975489213

http://orcid.org/0000-0001-6156-7287

patriciakischner@hotmail.com

Cristiane Ivete Bugs Vione (iD

Universidade Regional do Estado do Rio Grande do Sul, Brasil http://lattes.cnpq.br/5955217454501014

http://orcid.org/0000-0002-1730-5842

cristianevione@gmail.com

\section{Referencing this:}

FERNANDES, S. B. V.; KISCHNER, P.; VIONE, C. I. B.. Uma perspectiva das ações sustentáveis realizadas por uma empresa do ramo de agronegócio. Revista Ibero Americana de Ciências Ambientais, v.10, n.2, p.243-253, 2019. DOI: http://doi.org/10.6008/CBPC21796858.2019 .002 .0021 


\section{INTRODUÇÃO}

Diante do dinâmico processo de globalização presenciado nos últimos tempos é crescente a preocupação da população mundial com os entraves sociais e ambientais gerados pelo modelo de produção contemporâneo. Posto que grande parte das tecnologias de produção utilizadas pelas empresas atualmente desencadeiam vários efeitos nocivos ao meio ambiente e a saúde humana contribuindo para a emissão de poluentes e, consequente, perda de qualidade dos recursos naturais. $\mathrm{O}$ desafio que se coloca é enorme e passa por ecologizar a sociedade e as políticas públicas, ou seja, significa a introdução da variável ecológica onde antes só havia a preocupação econômica. Entretanto, essa nova visão não mexe essencialmente com o paradigma central do capitalismo, apenas otimiza os processos produtivos (NEIMAN et al., 2014).

Dentre as diferentes alternativas buscadas pela sociedade para solucionar estes entraves ambientais decorrentes do atual modelo de desenvolvimento econômico, a gestão ambiental representa uma ferramenta importante para a mitigação dos efeitos negativos dos processos realizados pela atividade empresarial. Por conseguinte, a avaliação dos impactos ambientais gerados pelos processos produtivos representa uma etapa imprescindível no contexto da gestão ambiental, tendo em vista que ela fundamenta todas as ações realizadas pelas organizações de diferentes setores da atividade econômica (FERNANDES et al., 2008).

A avaliação de impactos ambientais, embora seja um importante instrumento de política ambiental, ainda é uma ferramenta pouco explorada. Compreendê-la como um processo eficaz que possibilita definir, mensurar, monitorar, corrigir as possíveis causa e efeitos gerados por determinada atividade sobre o ambiente, representa importante alternativa em direção ao desenvolvimento local sustentável. Diante do exposto, o presente estudo propõe-se a verificar os impactos ambientais e as principais estratégias de atenuação realizadas por uma empresa do ramo do agronegócio situada na região Noroeste do Estado do Rio Grande do Sul.

O estudo justifica-se em função dos impactos e ações empreendidas pela atividade empresarial ser um tema de grande relevância no contexto atual, uma vez que a sociedade está mais preocupada com os efeitos ambientais gerados pelas atividades econômicas. Desse modo, temas relacionados a gestão e avaliação dos impactos ambientais tem se tornando um atrativo para a realização de pesquisas cientificas e acadêmicas.

O artigo está organizado em cinco seções, além desta introdução é apresentado o quadro teórico de referência que procura situar o contexto intelectual que sustentou o estudo. Na terceira seção, aborda-se a metodologia que orientou sua condução. Na quarta seção apresentam-se os resultados obtidos fundamentados na organização analisada. Por fim, são apresentadas as conclusões da investigação, bem como suas limitações e oportunidades para estudos futuros.

\section{REVISÃO TEÓRICA}

\section{Desenvolvimento Sustentável}


A iniciativa de desenvolvimento sustentável tem como marco principal a insatisfação de uma parcela da sociedade, com os limites da abordagem predominante capitalista baseada na utilização desordenada e predatória dos recursos naturais. Essa insatisfação é reflexo da conscientização, por parte das entidades sociais, acerca dos elevados níveis de deterioração da qualidade de vida da população e da crescente pressão da degradação ambiental sobre os ecossistemas.

Embora diversas inciativas pautando preocupações ambientais já estivessem em curso, a Conferência Mundial sobre Meio Ambiente de Estocolmo, em 1972, foi o marco mais importante no processo de conscientização da comunidade internacional sobre os limites do desenvolvimento econômico. Foi um período marcado por forte debate entre aqueles que defendiam o desenvolvimento a qualquer custo, mesmo pondo em risco a própria natureza e os partidários das questões ambientais (ROMEIRO, 2012).

Na década de 1980, a Organização das Nações Unidas retomou o debate sobre a crescente utilização e degradação dos recursos naturais nos processos de produção capitalista e, através da Comissão Mundial sobre o Meio Ambiente e Desenvolvimento, gerou o Relatório Brundtland, o qual propõe o desenvolvimento sustentável como aquele que busca promover a harmonia entre os seres humanos e a natureza, não se referindo apenas ao impacto da atividade econômica no meio ambiente. Diz respeito, principalmente, as consequências dessa relação na qualidade de vida e no bem-estar da sociedade tanto presente quanto futura (FERNANDES et al., 2008).

A definição completa que foi cunhada por esta Comissão vai muito além: está nas mãos da humanidade para tornar o desenvolvimento sustentável, isto é, garantir que atenda às necessidades do presente sem comprometer a capacidade das gerações futuras de atender também as suas. O conceito de desenvolvimento sustentável implica limites, não limites absolutos, mas limitações impostas aos recursos do meio ambiente o estado atual da tecnologia e organização social e a capacidade da biosfera de absorver os efeitos das atividades dos recursos humanos, mas tanto a tecnologia como a organização social podem ser geridas e aprimoradas a fim de proporcionar uma nova era de crescimento econômico (CMMAD, 1987).

A princípio, o reconhecimento de que existe uma contradição incontornável entre um estoque de recursos finitos, muitos dos quais irreprodutíveis na escala humana e um crescimento infinito apregoado pelo sistema econômico, parece ser inquestionável. Trata-se de reconhecer que o fator limitante fundamental não é a finitude do estoque de materiais não renováveis, mas de capacidade ecossistêmica de absorvê-los e manter um equilíbrio favorável à vida humana (ROMEIRO, 2012).

Desse modo, Veiga (2006) estabelece que a atividade econômica, o meio ambiente e o bem-estar da sociedade formam um tripé o qual fundamenta a ideia de desenvolvimento sustentável. A relação entre o desenvolvimento sustentável e gestão ambiental baseia-se no fato de que este último conceito é um condicionante para que o primeiro aconteça. Considerando que o conceito de desenvolvimento sustentável sugere um legado permanente de uma geração a outra, para que todos possam suprir suas necessidades, a sustentabilidade, ou seja, a qualidade daquilo que é sustentável, passa a incorporar o significado de manutenção e conservação permanente dos recursos naturais. Isso exige avanços científicos e tecnológicos 
que ampliem permanentemente a capacidade de utilizar, recuperar e conservar esses recursos, bem como novos conceitos de necessidade humanas para aliviar as pressões da sociedade sobre ele (BARBIERI, 2005).

Sen (2000) destaca que para ocorrer de fato um desenvolvimento satisfatório é necessário que se removam as principais fontes de privação de liberdade, ou seja, a pobreza, a carência de oportunidades econômicas e destituição social sistemática, a negligência dos serviços públicos e a intolerância ou interferência excessiva de Estados repressivos. Assim, o desafio reside em desenvolver a consciência coletiva de que todas as formas de relação do homem com a natureza devem ocorrer com o menor dano possível ao ambiente.

A atividade industrial é considerada o principal indutor de danos ao meio ambiente. Desse modo, implantação de padrões tecnológicos menos nocivos ao ambiente é uma condição necessária para que o crescimento econômico possa ser mantido e que, juntamente com a distribuição mais equitativa dos benefícios gerados por este crescimento, se caminhe na direçao do desenvolvimento sustentável.

\section{Avaliação do impacto ambiental da atividade empresarial}

A avaliação do impacto ambiental (AIA) é um instrumento de política ambiental utilizado para identificar e gerenciar os principais impactos do desenvolvimento econômico sobre o ambiente (BASSO et al., 2006). Trata-se de um conjunto de atividades técnicas e científicas que incluem o diagnóstico ambiental, a fim de, prevenir, medir e interpretar, quando possível, os impactos ambientais gerados por diferentes atividades. Conforme a Resolução expedida pelo Conama № 01/86 considera-se impacto ambiental:

qualquer alteração das propriedades físicas, químicas e biológicas do meio ambiente, causada por qualquer forma de matéria ou energia resultante das atividades humanas que, direta ou indiretamente, afetam: a saúde, a segurança e o bem-estar da população; as atividades sociais e econômicas; a biota; as condições estéticas e sanitárias do meio ambiente; a qualidade dos recursos ambientais.

Outra definição relevante elaborada pela NBR ISO 14001 engloba as atividades desenvolvidas pelas organizações empresariais, trata-se de "qualquer modificação do meio ambiente, adversa ou benéfica, que resulte, no todo ou em parte, das atividades, produtos ou serviços de uma organização". Conforme esta definição, qualquer atividade que modifique o ambiente, independentemente de sua importância, caracteriza-se impacto ambiental.

A avaliação de impactos ambientais é realizada através de vários métodos e envolve diversos grupos de interesse, como promotores de empreendimento, autoridades governamentais, especialistas, associações civis e outros setores relacionados (OLIVEIRA et al., 2001), que tem por objetivo central o auxílio no processo de tomada de decisão. Contudo, muitas vezes a avaliação de impactos ambientais, como instrumento da Politica Nacional do Meio Ambiente é considerada parte integrante das politicas de comando e controle das atividades poluidoras. Nessa condição, é considerada apenas um mero requisito administrativo, quando não um obstaculo ao desenvolvimento das atividades econômicas.

Floriano et al. (2007) destacam que o papel da gestão ambiental é garantir que todos os processos organizacionais funcionem em conformidade com o meio ambiente, através do estabelecimento de procedimentos que buscam reduzir e controlar os impactos ambientais causados pelas empresas, 
aprimorando seu relacionamento com o meio ambiente e com a sociedade. Assim, a avaliaçao de impactos ambientais constitui-se num dos principais elementos do processo de gestão ambiental.

\section{Gestão ambiental}

Jabbour et al. (2009) definem a gestão ambiental como o conjunto pertinente de ações, levado a cabo no contexto organizacional, que altera estrutura, responsabilidades, diretrizes, práticas administrativas e aspectos operacionais, para fazer frente à complexidade inerente à inserção da variável ambiental, atingindo expectativas e metas previamente estabelecidas, por meio da mitigação das externalidades negativas gerados pelas atividades empresariais. Em suma, percebe-se que gestão ambiental significa, responsavelmente, desenvolver, implementar e controlar estratégias que minimizem ou eliminem os danos causados ao meio ambiente por meio dos processos produtivos (FERREIRA, 2012).

Desse modo alguns autores (DONAIRE, 1994; BARBIERI, 2004) propõem três estágios evolutivos para análise da gestão ambiental empresarial. No primeiro estágio, há uma postura reativa da empresa perante as problemáticas ambientais e, assim, as questões ambientais são avaliadas pela empresa apenas como um custo operacional, decorrente de práticas para evitar maiores impactos ambientais. O segundo estágio, é o chamado preventivo, uma vez que a questão ambiental se torna uma variável relevante para o desempenho empresarial, embora, ainda não se perceba oportunidades de melhoria do negócio com base nas questões ambientais. Nessa fase, há uma reestruturação dos processos produtivos para que a poluição seja evitada. Finalmente, no último estágio a variável ambiental passa a ser considerada uma estratégia do negócio, de modo, que todas as áreas da organização passam a criar ações pautadas na preservação ambiental (FERREIRA, 2012), caracterizando-se então como uma abordagem proativa frente às das questões ambientais.

Sanches (2000) chama atenção para o fato que as empresas industriais que procuram manter-se competitivas percebem que diante das questões ambientais são exigidas novas posturas, seja na maneira de operar seus negócios, seja em suas organizações. Essa renovação implica contínuas mudanças, que podem ser custosas em termos financeiros e podem ser gerenciadas internamente mediante mecanismos de auto regulação ou por ações individuais. A auto regulação representa iniciativas tomadas pelas empresas ou por setores da indústria para empreender e disseminar práticas ambientais que promovam uma maior responsabilidade das empresas quanto às questões ambientais, mediante a adoção de padrões, monitorações, metas de redução da poluição e assim por diante. Trata-se, todas as formas de auto regulação, de iniciativas que marcam um novo contexto de participação do empresariado rumo à consciência e às responsabilidades ambientais, também com a preocupação de adequar os princípios de sustentabilidade à realidade dos mercados em que as empresas estão inseridas.

Do ponto de vista técnico, a gestão ambiental de empresas de qualquer nível, tamanho ou área é operada por princípios expressos na série ISO 14000, que compreende um conjunto de normas, cujo objetivo é orientar um Sistema de Gestão Ambiental, em acordo com todas as políticas e leis ambientais. O Sistema de Gestão Ambiental (SGA) é um dos principais instrumentos de auto regulação e têm se tornado um 
importante aliado das organizações que buscam manter seus processos e impactos ambientais sob controle, através da mitigação dos impactos e danos ambientais decorrentes da atividade empresarial. Oliveira et al. (2010) discorrem que "um sistema de gestão ambiental pode ser descrito como uma metodologia pela qual as organizações atuam de maneira estruturada sobre suas operações para assegurar a proteção do meio ambiente". Para Andreoli (2001):

a implementação de um SGA constitui uma ferramenta para que o empresário identifique oportunidades de melhorias que reduzam os impactos das atividades de sua empresa sobre o meio ambiente, orientando de forma otimizada os investimentos para implementação de uma política ambiental eficaz, capaz de gerar novas receitas e oportunidades de negócio.

Arruda et al. (2012) corroboram asseverando que a busca por novas perspectivas de crescimento e desenvolvimento econômico, em concordância com o melhor aproveitamento dos recursos naturais e a mitigação dos impactos ambientais, estruturaram a gestão ambiental nas empresas. Assim, para as organizações que optam por integrar a gestão ambiental a sua estratégia de negócio, cada decisão se torna uma oportunidade de criação de valor para impulsionar a inovação e a implantação de novas tecnologias nos processos e produtos realizados por esta.

Oliveira et al. (2010) destacam que a série de normas NBR ISO 14001 tem sido uma das ferramentas mais utilizado para desenvolver a gestão ambiental nas empresas. Os autores destacam que no Brasil, sua adoção vem aumentando consideravelmente nos últimos anos, indicando amadurecimento das questões ambientais empresariais na direção de uma gestão sustentável. Para Deroit (2006) este conjunto de normas ambientais, apresenta-se como um instrumento a ser utilizado, permitindo ao mesmo tempo o cumprimento da legislação ambiental, a proteção ao meio ambiente e melhoria da competitividade das empresas.

Desse modo, a implantação de um sistema de gestão ambiental pode resultar em diversos benefícios a organização. Em especial o aumento das relações comerciais e acesso a novos mercados, redução de riscos, maior controle e racionalização dos processos realizados pela empresa, melhoria na relação com colaboradores, melhoria da imagem pública e aumento da competitividade (FLORIANO et al., 2007).

Nesse sentido, empresas industriais adotam posturas proativas em relação ao meio ambiente mediante a incorporação dos fatores ambientais nas metas, políticas e estratégias da empresa. Entretanto, é fundamental que a proteção ambiental passe a fazer parte de seus objetivos de negócios e que meio ambiente não seja mais encarado como um adicional de custo, mas como uma possibilidade de lucros (SANCHES, 2000), mas que acima de tudo internalize um conceito de responsabilidade socioambiental. Para tanto, um longo caminho a percorrer pressupõe uma preocupação de educação ambiental em sentido amplo, com seu quadro funcional e, mais além, com a comunidade com a qual interage.

\section{METODOLOGIA}

O presente estudo de caso é de natureza teórico empírica, numa abordagem predominantemente qualitativa de cunho exploratório (MINAYO, 1994), explorando evidências empíricas sobre os impactos ambientais e as estratégias adotadas por uma empresa do setor de agronegócio localizada na região 
Noroeste do Estado do Rio Grande Do Sul. A escolha da empresa ocorreu de forma aleatória, após contato com diversas firmas do setor, a organização aqui pesquisada se dispôs a colaborar com o estudo.

O estudo parte de uma análise teórica sobre os conceitos de desenvolvimento sustentável, impactos ambientais e gestão ambiental empresarial, para isso, foram utilizadas obras de referência na área, bem como, estudos teóricos empíricos publicados em periódicos e eventos científicos que apresentam diferentes abordagens para a discussão do tema proposto.

A técnica de pesquisa utilizada para a coleta dos dados foi a entrevista semiestruturada realizada com os responsáveis pela gestão ambiental na empresa. O período de coleta dos dados foi de maio a junho de 2018. O roteiro da entrevista foi elaborado em blocos, sendo o primeiro destinado a identificação dos aspectos e impactos ambientais referentes ao segmento de atuação da empresa, seguido pela identificação e descrição das estratégias adotadas para a diminuição dos impactos ambientais e, por fim as ações sociais desenvolvidas.

O tratamento qualitativo dos dados permitiu a classificação das estratégias, categorizadas em ações reativas, preventivas e proativas, empregando-se para tanto a técnica de análise de conteúdo descrita por Bardin (1977) como "um conjunto de instrumentos metodológico que se aplicam a conteúdos extremante diversificados". Optou-se por agrupar as ações preventivas e proativas num único grupo, pela dificuldade de distingui-las com clareza, dado ao caráter exploratório do presente trabalho.

\section{RESULTADOS E DISCUSSÃO}

A empresa em tela atua com um total de 27 unidades distribuídas no estado do Rio Grande do Sul na comercialização de insumos, com um centro logístico voltado ao setor de distribuição de defensivos e também com uma planta de extração de óleo de soja produzindo farelo, óleo degomado e biodiesel. A partir do ano de 2017 iniciou o processo de exportação de grãos de soja, milho, trigo, cevada, farelos e óleo de soja para países da América Latina, Europa e Ásia.

Tomando como base para análise a investigação empírica, constata-se que, mesmo a empresa não dispondo de um Sistema de Gestão Ambiental (SGA) certificado pelas normas ISO 14001, apresenta diversas iniciativas condizentes com as características de gestão ambiental descritas na revisão teórica deste estudo. Essas iniciativas empresariais estão voltadas para a eficiência econômica, equidade social e respeito ao meio ambiente, como sustentado teoricamente por (BARBIERI et al., 2011).

As evidencias empíricas encontradas na empresa pesquisada, revelam os impactos ambientais e as respectivas ações realizadas para minimizá-los. Para fins desta pesquisa, as ações empresariais correspondentes à gestão ambiental são categorizadas em dois grupos. Conforme descrito no Quadro 1, primeiramente são elencadas as principais práticas reativas, condizentes com os aspectos determinados pela legislação ambiental. Na sequência, registram-se as práticas proativas desenvolvidas pela organização de forma consciente para a proteção ambiental.

Os resultados deste estudo confirmam que as ações de ajustamento aos aspectos legais tem sido o principal elemento de orientação do processo de gestão ambiental na empresa. De modo geral o 
atendimento aos aspectos legais representa majoritariamente as ações empreendidas pela empresa em relação à redução de seus impactos. Entretanto, constata-se também a realização de diversas ações proativas concomitantemente às ações reativas, isto aparentemente corresponde a um nível de percepção positiva da empresa com relação aos impactos ambientais decorrentes de sua atuação no mercado. Constata-se que há inciativas de ações voltadas à preservação ambiental que correspondem ao segundo grupo, das ações categorizadas como proativas.

Quadro 1: Impactos ambientais e estratégias de gestão ambiental realizados por uma empresa do ramo de agronegócio da região Noroeste do Rio Grande Do Sul.

\begin{tabular}{|l|l|}
\hline Setor de Atuação & Agronegócio \\
\hline $\begin{array}{l}\text { Principais Impactos } \\
\text { Ambientais }\end{array}$ & $\begin{array}{l}\text { Comercialização de produtos agropecuários e processos agroindústrias que resultam em contaminação } \\
\text { da água, contaminação do solo, desmatamento, emissão de } \mathrm{CO}_{2} \text {, resíduos de embalagens plásticas. }\end{array}$ \\
\hline \multirow{5}{*}{ Práticas Reativas } & $\begin{array}{l}\text { - Geração de laudos de emissões atmosféricas; } \\
\text { - Relatório de desmatamento de áreas verdes; } \\
\text { - Conservação de área de reserva legal; }\end{array}$ \\
& $\begin{array}{l}\text { - Manifesto de controle de resíduos (MTR); } \\
\text { - Relatório mensal de destinação de resíduos; }\end{array}$ \\
& - Auditoria ambiental bienal; \\
& - Coleta de material contaminante (pilhas e baterias). \\
\hline \multirow{3}{*}{ Práticas Proativas } & - Programa logística de reserva; \\
& - Adoção de geradores de energia movidos a combustíveis renováveis; \\
& - Programa de Produção e Uso de Biodiesel; \\
& - Constituição de um Comitê Socioambiental; \\
& - Ações socioambientais diversas na comunidade regional. \\
\hline
\end{tabular}

As ações proativas são as atitudes relacionadas ao princípio de preservação e envolvem o desenvolvimento de novos processos e produtos, reciclagem de resíduos, reaproveitamento de energia e integração com o meio ambiente (FERNANDES et al., 2008). Embora no limite todas as ações empreendidas, reativas ou proativas atendem a melhoria da qualidade ambiental e, por conseguinte beneficiam a sociedade, pode-se fazer uma distinção entre as ações de caráter eminentemente técnico das ações com foco socioambiental.

Fazem parte do grupo de ações reativas de caráter socioambiental o Programa de Produção e Uso de Biodiesel (Quadro 1) em que a empresa busca, de forma sustentável a produção e o uso do biodiesel, com o foco na inclusão social, via geração de emprego e renda, destacando-se que 40\% da matéria prima utilizada na produção é advinda da agricultura familiar. Já o programa de logística de reversa, que tem por foco a maior parte das embalagens de defensivos comercializados, recolhidas e encaminhados para reciclagem, situa-se entre as ações de caráter técnico.

Dentre o conjunto de ações categorizadas como proativas merece destaque o fato de a organização ter criado um comitê socioambiental composto por colaboradores voluntários, de diferentes setores da empresa, que buscam, para além de cumprir com os aspectos legais impostos pela legislação ambiental, o desenvolvimento de ações internas e externas voltadas ao meio ambiente e à sociedade. Logo, além de atender a legislação, a empresa estimulou uma série de ações e projetos que visam inclusão social, tanto no ambiente próximo, como no espaço territorial mais amplo, na área de abrangência dos negócios da organização. 
Outra ação proativa, de caráter técnico foi a substituição de geradores movidos a combustíveis fósseis, por geradores movidos a combustíveis renováveis. São ações aparentemente simples, mas que contribuem para a geração de uma cultura de responsabilidade socioambiental, que podem gerar externalidades positivas na medida em que exercem influência sobre outras organizações que interagem no território.

Evidenciou-se através da análise empírica que os gestores têm conhecimento dos impactos que os processos de produção decorrentes de suas atividades podem provocar ao meio ambiente. Portanto, essa percepção tem desencadeado o desenvolvimento de ações que vão além do atendimento à legislação ambiental, uma vez que compreendem que além de 'saúde financeira' positiva, a empresa deve respeitar e melhorar o ambiente onde está inserida.

Constatou-se também que os principais desafios enfrentados pela organização na implantação de práticas de gestão ambiental estão centrados em dois aspectos principais: custos financeiros e a educação ambiental. Conforme descrito pelos responsáveis pela gestão ambiental da empresa, algumas ações demandam montantes financeiros elevados, ademais, as pessoas ainda não têm um comprometimento com o meio ambiente e isso dificulta a implantação de algumas práticas.

A educação ambiental deve ser um processo contínuo de reforço a valores, mas também a conhecimentos que permitam desenvolver as capacidades necessárias para a participação social efetiva, incorporando conceitos e metodologias novas que venham ao encontro da realidade, influenciando nas mudanças de atitudes e possibilitando o desenvolvimento de um olhar crítico atuante diante das situações socioambientais.

Para solucionar este entrave à organização fortaleceu o comitê socioambiental incluindo colaboradores de diferentes áreas da empresa e, através deste, estabeleceu coletivamente a sua política socioambiental. Evidenciou-se através da análise empírica que diversas ações sociais são desenvolvidas por este comitê, dentre as quais destaca-se: o projeto de prevenção de câncer de mama, em que são realizadas orientações sobre a doença e sua prevenção; acolhimento dos familiares dos colaboradores em visitas à empresa, assim como sua participação em comemorações festivas da organização. Além deste, destaca-se o projeto de apoio à Associação de Pais e Amigos dos Excepcionais - APAE em que são realizadas doações mensais de cestas básicas a instituição.

Jabbour et al. (2009) enfatizam que "para evoluir rumo a estágios mais avançados de gestão ambiental é requerida a incorporação da dimensão ambiental nas práticas de recursos humanos, adicionando-se a esse processo transformações ambientais em outras áreas de gestão". Sob esta lógica Medeiros et al. (2015) acrescenta que, uma das maneiras de se obter vantagem competitiva sem comprometer muitos recursos financeiros é adotar medidas socioambientais cuja implementação e resultado tornem-se atraentes aos olhos de seus consumidores e constituam-se em diferencial perante à concorrência. Desse modo, ações socioambientais voltadas para aos interesses da sociedade tem se tornado uma estratégia de marketing implantado por diversas empresas de vários setores econômicos. 


\section{CONCLUSÕES}

Dentre as diversas formas buscadas pelas organizações para mitigar os efeitos de seu desenvolvimento econômico ao meio ambiente, a gestão ambiental representa uma concepção de enfrentamento das principais externalidades negativas do processo produtivo dos diferentes setores da economia. Dado que, o mercado tem exigido das organizações uma nova postura frente ao desenvolvimento de métodos e técnicas, para concepção de produtos e serviços mais eficientes do ponto de vista ecológico, a consideração de ações socioambientais trata-se de estratégia não negligenciável na conquista, tanto de um diferencial competitivo, como um passo para a paulatina construção de uma sociedade sustentável.

O estudo desenvolvido em empresa da região Noroeste do Estado do Rio Grande do Sul revelou que está, de modo geral, têm buscado atender os requisitos da legislação ambiental, correspondendo a uma estratégia reativa. Contudo percebe-se que há iniciativas de ações voltadas à dimensão socioambiental que correspondem a práticas proativas.

Com relação a avaliação de impactos ambientais, embora um importante instrumento de política ambiental, ainda é uma ferramenta pouco explorada pelas empresas. Desse modo, compreendê-la como um processo eficaz que possibilita definir, mensurar, monitorar possíveis causas e efeitos gerados por determinada atividade sobre o ambiente representa um importante ensejo em direção ao desenvolvimento local sustentável. Decorrente das incipientes iniciativas na avaliação de impactos ambientais, a gestão ambiental empresarial assume um caráter reativo, voltando-se ao atendimento a requisitos legais. Entretanto, ações socioambientais, de natureza voluntária tem sido implementada, revelando a expectativa de um processo evolutivo no sentido de paulatina afirmação de conceitos e práticas alinhadas ao desenvolvimento sustentável.

Por fim, cabe ressaltar como limitação deste trabalho o fato da coleta de dados ter sido realizada com os responsáveis pela gestão ambiental na empresa avaliada, este alto grau de envolvimento com o sistema pode influenciar a formulação das respostas. Contudo, são esses profissionais que têm uma visão geral e maior conhecimento sobre a gestão ambiental. Desse modo, considera-se para estudos futuros análises direcionadas a todos os setores da organização, com vistas a captar informações mais abrangentes e detalhadas e sobre o tema proposto.

\section{REFERÊNCIAS}

ABNT. Associação Brasileira de Normas Técnicas. N14004: sistemas de gestão ambiental-diretrizes gerais sobre princípios, sistemas e técnicas de apoio. Rio de Janeiro: ABNT, 1996.

ANDREOLI, C. V.. Gestão ambiental. In: Gestão empresarial. 2001. p.61-70.

ARRUDA, A. G.; FARIA, A. C.; SILVA PEREIRA, R.; OLIVEIRA, S. M.; SILVA, T. N.. Gerenciamento ambiental no setor sucroalcooleiro: um estudo de caso na pioneiros bioenergia sa. Gestão e desenvolvimento, v.9, n.1, p.21-32, 2012.
BARBIERI, J. C.. Desenvolvimento e meio ambiente: as estratégias de mudanças da Agenda. Petrópolis,: Vozes, 2005.

BARBIERI, J. C.. Gestão ambiental empresarial. Saraiva, 2004.

BARBIERI, J. C.; SILVA, D.. Desenvolvimento sustentável e educação ambiental: uma trajetória comum com muitos desafios. Revista de Administração Mackenzie, v.12, n.3, p.51-82, 2011.

BARDIN, L.. Análise de conteúdo. Lisboa: Edições 70, 1997. 
BASSO, L. A.; VERDUM, R.. Avaliação de Impacto Ambiental: Eia e Rima como instrumentos técnicos e de gestão ambiental. In: Relatório de impacto ambiental: legislação, elaboração e resultados. Porto Alegre: UFRGS, 2006.

COMISSÃO MUNDIAL SOBRE MEIO AMBIENTE E DESENVOLVIMENTO. Nosso Futuro Comum. Rio de Janeiro: Fundação Getúlio Vargas, 1987.

DAROIT, D.. A teoria organizacional e o tratamento econômico da gestão ambiental. In: ENCONTRO NACIONAL DOS PROGRAMAS DE PÓS-GRADUAÇÃO EM ADMINISTRAÇÃO. Anais. 2006.

DONAIRE, D.. Considerações sobre a influência da variável ambiental na empresa. Revista de administração de empresas, v.34, n.2, p.68-77, 1994.

FERNANDES, S.; TEIXEIRA, E.; GADONSKI, M.; GRZYBOVSKI, D.. Impactos e estratégias ambientais: uma análise em empresas da Região Noroeste do Estado do RS. Revista de Estudos de Administração, v.9, p.171-190, 2008.

FERREIRA, M. C.. Gestão Ambiental: práticas, condicionantes e evolução. Revista de Administração IMED, v.2, n.2, p.138150, 2012

FLORIANO, F.; SOUZA, A. E. D.; CORRÊA, H. L.. Impacto ambiental: estudo no arranjo produtivo local de calçados de São João Batista/SC. In: ENCONTRO NACIONAL DE PÓSGRADUAÇÃO EM ADMINISTRAÇÃO. Anais. 2007.

JABBOUR, C. J. C., SANTOS, F. C. A., NAGANO, M. S. Análise do relacionamento entre estágios evolutivos da gestão ambiental e dimensões de recursos humanos: estado da arte e survey em empresas brasileiras. Revista de Administração da Universidade de São Paulo, v.44, n.4, 2009.
MEDEIROS, M. D. S. B.; BARBOSA, R. F.; SOUSA, J. E.; ALEXANDRE, S. N.; OLIVEIRA, C. G. S.. Gestão ambiental e sustentabilidade um estudo de caso na agência do Banco do Brasil de Alagoa Nova/PB. REGET, v.19, n.3, 2015.

MINAYO, M. C.. Pesquisa Social. Teoria, Método e Criatividade. Rio de Janeiro: Vozes, 1994.

NEIMAN, Z.; RABINOVICI, A.; SOLA, F.. A questão ambiental, a sustentabilidade e inter, pluri ou transdisciplinaridade. In: Sustentabilidade ambiental: estudos jurídicos e sociais. 2014. p.24.

OLIVEIRA, A. A. D.; BURSZTYNB, M.. Avaliação de impacto ambiental de políticas públicas. Interações, Campo Grande, v.2, n.3, 2001

OLIVEIRA, O. J. D.; SERRAB, J. R.. Benefícios e dificuldades da gestão ambiental com base na ISO 14001 em empresas industriais de São Paulo. Revista Produção, v. 20, p. 429438, 2010.

ROMEIRO, A. R.. Desenvolvimento sustentável: uma perspectiva econômico-ecológica. Estudos avançados, v.26 n.74, p.65-92, 2012.

SANCHES, C. S.. Gestão ambiental proativa. Revista de Administração de Empresas, v.40, n.1, p.76-87, 2000.

SEN, A. E. N.. Desenvolvimento como liberdade. São Paulo: Companhia das Letras, 2000.

VEIGA, J. E. D.. Meio ambiente \& desenvolvimento. São Paulo: Senac, 2006.

A CBPC - Companhia Brasileira de Produção Científica (CNPJ: 11.221.422/0001-03) detém os direitos materiais desta publicação. Os direitos referem-se à publicação do trabalho em qualquer parte do mundo, incluindo os direitos às renovações, expansões e disseminações da contribuiç̃o, bem como outros direitos subsidiários. Todos os trabalhos publicados eletronicamente poderão posteriormente ser publicados em coletâneas impressas sob coordenação da Sustenere Publishing, da Companhia Brasileira de Produção Científica e seus parceiros autorizados. Os (as) autores (as) preservam os direitos autorais, mas não têm permissão para a publicação da contribuição em outro meio, impresso ou digital, em português ou em tradução. 